\title{
Developing Effective Intercultural Relationships: The Importance of Communication Strategies
}

\author{
Michael G. Harvey - David A. Griffith
}

\begin{abstract}
Executive Summary
As global competition intensifies, it is becoming necessary for organizations to establish strong intercultural relationships with a culturally diverse set of employees, interorganizational partners as well as customers. In order to manage these relationships effectively, organizations need a means to understand and improve global intercultural communications. The complexity of intercultural communications requires management to understand the nature of domains of global relationships and the level of complexity when attempting to communicate with multiple partners having unique national and organizational cultures. In this article, a decision process for developing effective intercultural communication strategies is developed, illustrating the steps necessary for managing a myriad of intercultural relationships. (C) 2002 Wiley Periodicals, Inc.
\end{abstract}

" . . a basic premise of relationship marketing is the need for executional consistency among all marketing communication strategies so that trust can be built ...” (Duncan \& Moriarty, 1998)

\section{INTRODUCTION}

he rapid growth of and resulting attention to relationship development-i.e., an integrated effort to identify, maintain, and build up a network of relationships with employees, interorganizational partners, and customers for mutual benefit of all members of the network - can have significant impact on the need to develop an integrated communication strategy (Shani \& Chalasani, 1992; Morgan \& Hunt, 1994). Nowhere is this acceleration in relationship development having a greater impact than in the global marketplace. For McDonald's, its ability to effectively communicate with employees, interorganizational partners, and customers across more than 115 countries determines not only the success of the corporation, but of partner firms as well.

Michael G. Harvey is the Puterbaugh Chair of American Free Enterprise and Professor of Global Business Policy at the Michael F. Price College of Business at the University of Oklahoma. David A. Griffith is an associate professor of Marketing at the University of Hawaii.

Thunderbird International Business Review, Vol. 44(4) 455-476 • July-August 2002 
Relationship development is based upon two distinct but related outcomes. First, relationship efficiency focuses attention on reducing the direct transaction cost associated with the exchange process between relationship members and, at the same time, increasing the volume of exchange between members, thereby reducing the cost per unit of the exchange (Williamson, 1991; Shani \& Chalasani, 1992). It is also anticipated in the long run, due to cooperation reducing the likelihood of short-run maximization decisions by members, that overall transaction expenditures will decline (Grönroos, 1994; Berry, 1995; Gundlach, Achrol, \& Mentzer, 1995; Pruden, 1995; Florin, 1997). Second, the relationship should also increase the effectiveness of the network of organizations, thereby differentiating network from less "coordinated" competitors.

This poor communication delayed the introduction of the car for nearly 18 months.
Therefore, relationship effectiveness can be derived from better service to existing customers as well as more attractive marketing services/benefits when compared to competitors who do not have effective ongoing relations (Barney, 1991; Stalk, Evans, \& Shulman, 1992; Collins, 1994; Henderson \& Cockburn, 1994; Teece, Pisano, \& Shuen, 1994). However, to ensure the increase in efficiency and in effectiveness, members need to communicate with network members appropriately. Failure to effectively communicate in intercultural relationships - whether with one's employees, interorganizational partners, or customers - can hamper relationship development, thus diminishing value delivery and competitiveness. Frequently, firms encounter difficulties when customers, channel members, and/or suppliers are in different countries. For example, Ford Motor Co. had significant difficulty with the introduction of the "Asian Ford" due to the United States' design team inability to effectively communicate with the strategic alliance partners in China and with suppliers spread throughout Asia. This poor communication delayed the introduction of the car for nearly 18 months.

Given the growth and strategic importance of relationships, understanding communication's underlying role is an important issue (Heide \& John, 1992; Inkpen, 1997; Voss \& Voss, 1997). This article addresses the need for and means to improve intercultural relationships through communication by presenting a process model of global relationship communication (see Figure 1). The article is divided into four sections, with each section detailing an element of the global relationship process model: (1) impact of the global market on the rationale for increased relationship development; (2) identification of domains of relationships; (3) influence on communications by national and organizational culture; and (4) development of an intercultural communications decision process. Each of these sections will be discussed in an 
Figure 1. Analysis of Global Relationship Communication Process

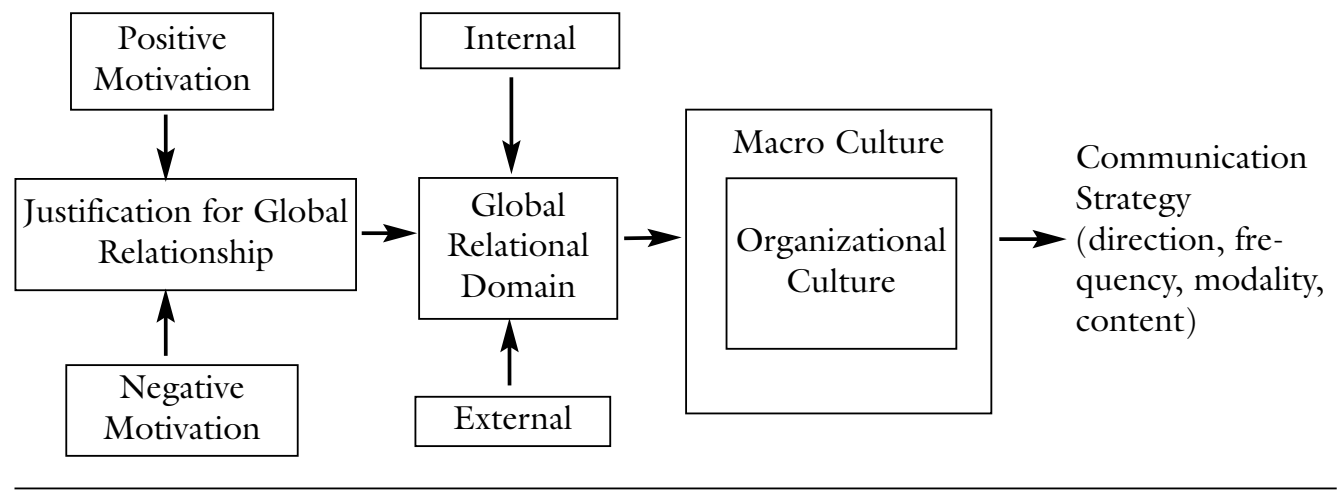

effort to illustrate the complexity and variability of developing integrated communication strategies for global relationships.

\section{IMPACT OF GLOBAL MARKET ON RATIONALE FOR INCREASED RELATIONSHIP DEVELOPMENT}

For many organizations, the move from a multinational strategy to a global one is a frame-breaking change and will have a significant impact on marketing functions, such as communication, that facilitate relationship development (Dyer \& Singh, 1998; Jeannet, 2000). The global relationship communication process is influenced by a number of factors, such as motivational elements, domain factors, and cultural compatibility, that determine the effectiveness of a firm's global communication strategy.

The growth in the importance of emerging markets (i.e., China, Indonesia, India, Malaysia, etc.) constitutes a major growth opportunity in the evolving world economic order (Arnold \& Quelch, 1998). It is estimated that seven-eighths of the world's population will reside in the emerging markets by the year 2025 (Garten, 1996; 1997). These markets are characterized by rapidly expanding populations, low per capita income, accelerating urbanization, economic instability (and, in many cases, political), and antiquated infrastructure. The cultural and social distance between these emerging markets and the manufacturers in developed countries accentuate the need for straightforward communication objectives between strategic alliance partners. SmithKline Beecham (SKB) developed a "corporate code" that communicates that its global relationships should be the benchmark of success in their industry. SKB communicates to each relationship part- 
ner that it aims to meet the global standards of integrity with its partners just as Xerox, Monsanto, American Express, British Petroleum, Barclays, Reuters, and Gillette do in their ongoing relationships. The ex ante standards of communication with suppliers and customers establishes a global standard that SKB is willing to be held to and will hold their suppliers to in their relationships.

The magnitude of differences among these countries/cultures and the developed economies of the West will accentuate the difficulties in establishing relationship networks. Given the perceived problems associated with establishing and maintaining relationships in emerging countries, the fundamental rationale for forming such alliances must be examined. The need for global relationship couplings could be motivated by any/all of the following issues:

1. Reaching new markets-relationships provide the means to expand rapidly enough to "race the world" for market coverage in global and emerging markets (Doz \& Hamel, 1998)

2. Producing economies of scale through economies of scopethe combination of resources among the partners provides the resource base to be more efficient in the total operation. The

Relationships provide the mechanism for changing the costs and risks associated with new ventures in countries where the organization has limited experience. leveraging of co-specialized resources provides the basis for development of competitive relative advantage (Florin, 1997).

3. Sharing and/or risk reduction - the scope of global marketing has increased the risks associated with competing in a multitude of markets. Relationships provide the mechanism for changing the costs and risks associated with new ventures in countries where the organization has limited experience (Gomes-Casseres, 1996).

4. Developing complementary contributions of partners' "skills" across the value chain-the skill set of the partnership is increased due to the unique combination of skill bases of the partners. The "plugging" skill gaps allows members in the network to more effectively compete in the local marketplace (Lorange \& Roos, 1992).

5. Building critical mass, resulting in barriers to effective competitive strategies - the size and competitive force of the relationship represents an entry barrier to competitors who are contemplating competition against the relationship. The economic mass and relationship scope create a large barrier for competitors to overcome (Buckley \& Casson, 1997).

6. Establishing "nodal" positions - the relationship can provide a geographic and institutional competitive advantage, taking 
that opportunity away from competitors. These positional assets provide the relationship coalition with difficult-to-replicate strategies for competitors (Craig \& Douglas, 1996; Doz \& Hamel, 1998).

7. Provides the mechanism for reciprocal learning and technology flows-the interrelationship among relationship partners stimulates the learning environment and encourages the exchange of proprietary information and technology with relationship partners to improve the relationship's efficiency and effectiveness (Papanastassion \& Pearce, 1997).

While there are additional potential benefits that can be derived from relationships, the aforementioned reasons listed for forming relationships, although not an exhaustive rationale, provides an understanding of the basic foundation logic for the rapid expansion of global relationship development. For example, The Coca-Cola Co., although using a standardized advertising strategy for decades, has more recently encouraged their local bottlers to provide their tacit/local knowledge to customize some of the nonelectronic media to national/regional demands. This strategy improves the communications with potential consumers and employs the insight/knowledge of the local distributor, thereby increasing the distributor's bond with The Coca-Cola Co. It is important to note that relationships are not generic, and to derive the maximum benefits from the wide variety of global relationships, it is necessary to delineate the various types of relationships that can be formed. The relationship type's resulting impact necessitates a different communication strategy and can become a central issue when maintaining a global relationship.

\section{DELINEATION OF GLOBAL RELATIONSHIP DOMAINS AND THE RESULTING IMPACT ON COMMUNICATIONS}

The literature in Europe and the United States is replete with articles examining relationship development within a channels-of-distribution, or other interorganizational contexts (Boyle, Dwyer, Robicheaux, \& Simpson, 1992; Grönroos, 1994; Gummesson, 1996; Fournier, Dobscha, \& Mick, 1998). However, it is important to note that relationships can exist among a variety of different populations of potential partners (Webster, 1992; Sagrero \& Schrader, 1998). While other researchers have applied relationship development to additional special-interest groups, the domain (i.e., cate-

It is important to note that relationships are not generic... 
gories of different types) of relationships has not been well-articulated (Dwyer, Schurr, \& Oh, 1987; Heide \& John, 1990; Grandori \& Soda, 1995).

In an effort to better understand the global communication challenges relative to relationship development, it is important to fully delineate the potential field of partners. The potential scope of global relationships can be referred to as the global relationship domain. It is important to not only identify that communication linkages can be (1) intra-organizational relationships, (2) interorganizational relationships, and (3) organizational-to-customer relationships, but also to realize their implications for overall intercultural relationship network development.

\section{Intra-organizational}

In a global context, the focal organization may represent a "for-

Selecting and implementing an integrated communication strategy to these internal partners (employees) must receive the highest priority... eign" entity to the host country's national employees and managers; therefore, a common relationship bond has to be formed with these employees. One of the first relationships that have to be forged is with those internal to the organization itself. Host country nationals frequently have a stereotypic attitude toward foreign employers, particularly when the cultural distance between the two countries is significant. Without first focusing attention on developing internal relationships, organizational efforts could be severely impeded. Selecting and implementing an integrated communication strategy to these internal partners (employees) must receive the highest priority (Gilly \& Wolfinbarger, 1998). Yet it should be recognized that one communication strategy will not fit all internal partners, given the number of countries the focal organization is operating in and the individual differences between cultures (Teece, Rumelt, Dosi, \& Winter, 1994; Reeves-Ellington \& Anderson, 1997; Gudykunst, 1998; Williams, Han, \& Qualls, 1998). The customization of communication strategies to internal partners recognizes the varying levels of commitment, trust, and cultural distance between the host and home country (i.e., employer-employee relationship) necessary for effective relationship development.

Another type of internal communication concern is between organizational entities of the same focal organization. In this situation, the exchange of information, data, or knowledge is not transferred among the functional or operating units, reducing their effectiveness. For example, Soderberg and Haak, a steel company in Sweden, had 
significant communication problems between divisions in the company. Sales personnel from different divisions showing up to sell different types of steel to the same customer on the same day exemplifies these lapses in division-to-division communications (Johanson, 1994). In many cases, the salesmen become competitors to each other and frequently provided price incentives, which eroded their division's profit margins as well as those of the entire corporation. Without internal coordination between operating units, the ability to coordinate marketing and selling activities to a common base of customers can be aggravated. Like the Exxon Alaskan oil spill of the late 1980s, which was public relations nightmare for the company, the management had to first communicate to the employees its companies' strategies to address the crisis. This was done prior to the communications with the general public. It was felt that without the employees behind the cleanup, the program would not be successful or be perceived as being successful.

\section{Interorganizational}

While the internal domain of relationship development is critical, with few exceptions (Lusch, Brown, \& Brunswick, 1992; Brown \& Bond, 1995; Gilly \& Wolfinbarger, 1998), past researchers of relationship marketing have focused on the external relationship opportunities-typically between organizations, such as relationships between members in the channel of distribution (cf., Gummesson, 1996). Intercultural interorganizational relationships consist of members that may be in a number of different countries, and the extent of national cultural differences between the countries may range a great deal, thus directly influencing communication strategies. Interorganization relationships include a broad spectrum of relationships, such as strategic alliance partners, structural support partners (such as financial institutions and advertising agencies), and noninteracting third parties (e.g., World Bank, International Monetary Fund, environmental groups, and other special-interest groups, in each of the foreign countries) and host governments.

The intercultural communication strategies between an organization and its interorganizational partners should not only provide a "link" that allows the communication goals to be achieved but should also foster the development of the relationship, much as communication efforts are aimed at fostering the relationship between the firm and its customers. In Germany in the 1980s, cooperation between manufacturers and retails in the area of supply-chain network management were sporadic. In the 1990s, due to increasing import

Thunderbird International Business Review • July-August 2002
Without internal coordination between operating units, the ability to coordinate marketing and selling activities to a common base of customers can be aggravated. 
competition and direct-product profitability, quick-response partnership, and efficient consumer response EDI systems, the level of coordination was increased through a more effective communications network and strategy initiated by large retailers (Araujo \& Mouzas, 1998).

When service is needed, both the salesperson and the customer service representative interact with the customer.

\section{Organization-to-Customer}

Lastly, another critical external relationship central to relationship development is the tie between the organization and its customers (individuals, as well as collectively or groups). Past research has focused on how to identify and satisfy consumer needs and building brand loyalty. Service marketing has also used relationship development as a platform for illustrating the value of service in ongoing relationships with customers (Treacy \& Wiersema, 1994; Sheth \& Parvatiyar, 1995). Two dimensions frequently are used to characterize the relationship with consumers: reduced transaction uncertainty (i.e., consumer avoidance of performance unpredictability, lower performance satisfaction, and/or unfavorable interactions relative to service) inclusive of trust, commitment, and confidence (Bendapudi \& Berry, 1997; Berry, 1995; Kasulis \& Balazs, 1998; Sheth \& Parvatiyar, 1995) and meaningful affiliation (i.e., the operative elements of meaningful affiliation are: (1) functional-the utility derived from the product/service; (2) social-a feeling of confidence and willingness to repurchase from the same organization; and (3) structural-mechanisms/processes that bind the consumer to future relationship interactions (Czepiel, 1990; Berry \& Parasuraman, 1991; Berry, 1995).

Frequently the organization-to-consumer relationship is tied to effective sales personnel and customer service representatives. The coordination of these two communication vehicles is seldom coordinated, and therefore, confusion and conflict over miscommunication can occur. At Sewell Village Cadillac in Dallas, Texas, these communication miscues are reduced because sales personnel have assigned customer service representatives are provided with all communications concerning new customers and who make contact with their salespersons' customers on a regular basis prior to any service problems with the automobile. Each communication effort is sent to the salesperson. When service is needed, both the salesperson and the customer service representative interact with the customer. Both the salesperson and the customer service representative must sign off on the customer before the service encounter is considered closed. The dealerships service satisfaction rating is in the top $5 \%$ in the United States. 


\section{INFLUENCE OF MACRO- AND ORGANIZATIONAL CULTURE ON RELATIONSHIP COMMUNICATIONS}

A major obstacle to successful global relationships is cultural distance (i.e., the extent to which the norms and values of the two societies differ) between the macrocultures of the participants (Killing, 1983; Harrigan, 1985; Geringer \& Herbert, 1990; Lewis, 1990; Park, 1991; Williams, Han, \& Qualls, 1998). Cultural distance can be viewed as differences in both the underlying macro/societal culture and organizational culture. The interaction of the external macroculture and the internal corporate culture can provide the foundation for understanding the complexity in the intercultural communication environment across the domain of global relationships.

In an effort to illustrate the influence of national culture and organizational culture on interorganizational communication, Figure 2 is presented below. This subdivision of both cultures is based on three

\section{Figure 2. Intercultural Communication Matrix}

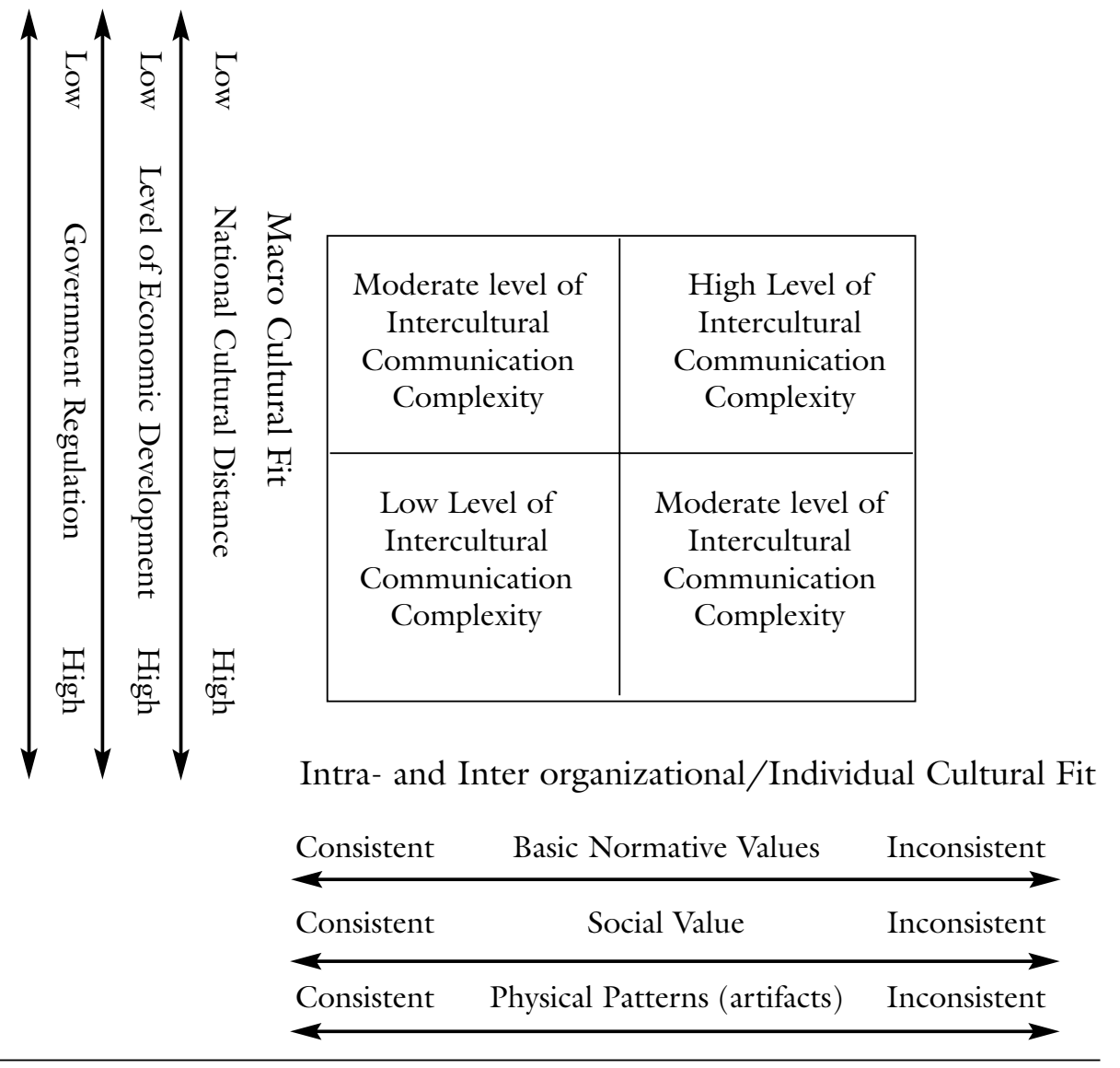


well-established constructs for each cultural setting. In the case of the macroculture: (1) cultural distance (i.e., the level of cultural novelty between two national cultures); (2) level of economic development (i.e., less developed, developing, developed); and (3) the level of government regulation/influence on organizations/industries/communications is viewed as a governor to interaction (e.g., level of industrial openness as indicated by government regulation and/or intervention).

Culture fit among partners has also been identified by using three commonly used constructs: (1) basic normative values, beliefs, and expectations of the organizational culture; (2) social or prescriptive values on how communication/personal interactions should be con-

Macroculture is composed of the norms and values members hold, as well as their level of economic development and regulatory environment share. ducted; and (3) physical patterns or artifacts that establish acceptable material aspects of an organizational culture. While other dimensions of cultural fit culture can directly influence relationship communication (e.g., management level sending and receiving communication, the level of control by management, the requirement of having communications-i.e., reporting), the three constructs selected encompass a significant portion of cultural elements. The macro/societal culture represents a distinct way of life of a group of people. Macroculture is composed of the norms and values members hold, as well as their level of economic development and regulatory environment share. Therefore, it is frequently held that when individuals encounter cultural differences in their interactions/relationships, they tend to view people from different macrocultures as strangers (i.e., unknown people who belong to different groups). Such intercultural interactions may lead to intercultural communication apprehension and miscommunications (Gundykunst, 1995; Neuliep \& McCroskey, 1997). This feeling of distance and misapprehension can directly impact trust, personal bonding, and long-term compatibility, which increases the probability of conflict among the individuals (Tjosvold, 1991, 1993; Tjosvold \& Wong, 1994).

While the "macro" dimension of culture has frequently been discussed as having a direct impact on group and individual behavior, the influence on communication strategy is noteworthy. Rather than focusing on macroculture as only a broad categorical influence on communication, it is important to recognize that the greater the macrocultural distance between those attempting to effectively communicate, the less likely that there will be sufficient "bonding" between individuals to facilitate effective communication. Bonding is essential in building the trust in relationships that is necessary for long-term relationships (Parkhe, 1998). Bonding is typically conceptualized between two types of social connectiveness: structural (i.e., 
task, context, and environment dimensions of relationship behavior) and social-i.e., affiliation, cooperation, sociability-(Spitzberg \& Lane, 1983). Structural bonding reflects the degree to which certain environmental elements of interaction between individuals from two macrocultures link/repel the individuals attempting to build longterm communication interactions on a personal or organizational level. Social bonding, on the other hand, is related to reducing the "stranger" orientation to another individual from a different macroculture, thereby increasing communication satisfaction and over time building trust (Williams, Han, \& Qualls, 1998). The impact of macrocultural distance on social/structural bonding can have a significant influence on commitment (individuals as well as organizations) to a relationship and therefore is a critical macrocultural dimension in the interorganizational communication equation.

Similarly, organizations are themselves cultural systems. Organizational cultural differences have been observed to impact the success of intercultural organizational interactions (Hamada, 1989; Garsten, 1993). The pattern of shared behaviors, values, and beliefs that provide a foundation to understand the organizational functioning processes and norms of behavior is recognized as organizational culture (Schein, 1985; Deshpendi \& Webster, 1989; Rousseau, 1990; Chatman \& John, 1994). Differences in organizational cultures can lead to the deterioration of joint efforts (Fey \& Beamish, 2000), as was the case in the proposed deal between American Home Products Corp.'s centralized and conservative culture and the relatively risk-taking organizational culture of Monsanto. When two or more organizations are interacting (communicating) the relative level of consistency of core elements between organizational cultures can directly influence the effectiveness of communication. Analysis of the core cultural values, ethics, and norms is necessary to develop a better understanding of the ontology of an organization's culture and the subsequent communication strategy to be used in relationship interactions (Reeves-Ellington \& Anderson, 1997). For example, in response to such concerns, British Telecom, when looking to partner with AT\&T, commissioned a cultural audit to examine the attitudinal and communication aspects of each firm prior to establishing cooperative programs.

Organizational culture is an amalgamation of the external macroculture and the backgrounds of individuals assembled in the organizational setting (Schein, 1996). The level of individuals' cultural heterogeneity can directly influence the commonly shared values, norms, and behaviors in the organization. Frequently, inconsistency of values, norms, and
Analysis of the core cultural values, ethics, and norms is necessary... 
behavior is most noticeable when employees from a different culture (e.g., expatriates) are combined with host country nationals (Mennell 1990). These two distinct cultures could have a significant variance in social knowledge (i.e., a view of the world in specific contexts and

...two diverse cultural viewpoints may accentuate misinterpretations of specific intercultural communications. resulting normative value set) and thereby have difficulty in communicating with each other. At the same time, while communicating, the two diverse cultural viewpoints may accentuate misinterpretations of specific intercultural communications. For example, a communication from one organization utilizing a total quality management (TQM) culture to another organization not utilizing a TQM orientation could easily be misinterpreted to mean production costs will be higher; whereas the TQM culture recognizes that customer loyalty and potential switching costs will be higher for the customer, thus improving the opportunity for long-run profitability. The differences between organizational cultures are frequently around these interrelated heuristics of the basic or normative values, social values, or prescriptive ethics and the physical patterns or artifacts of interaction and communication (Trompenaars, 1993; Schwartz, 1994; Smith et al., 1996; ReevesEllington \& Anderson, 1997; Hofstede \& Bond, 1998).

The overall complexity of a firm's communication environment will vary tremendously when elements of macroculture and organizational culture are examined. In instances where a high level of macrocultural distance exists and the organizational cultures are inconsistent, a firm's communication environment will be highly complex, necessitating careful planning and monitoring of its employed intercultural communication strategies. Alternatively, when macrocultural distance is low and organizational cultures are consistent (i.e., a low level of intercultural communication complexity), a firm will find it easier to employ effective communication strategies without adaptations. Given the potential complexity of the communication environment and the scope of a firm's relationship domain, the development of a process for intercultural communication strategy is necessary.

\section{DEVELOPING AN INTERCULTURAL COMMUNICATION STRATEGY}

Communication strategies are posited as being composed of four individual elements: (1) direction, (2) frequency, (3) modality, and (4) content (Mohr \& Nevin, 1990). Direction refers to whether the movement of communication between the parties to the transaction is uni- or bidirectional (Miller, 1999; Mohr \& Nevin, 1990). Frequency of communication is a measure of the amount of commu- 
nication between the members (Mohr \& Nevin, 1990). Modality refers to the level of the medium's personalization, or what is frequently referred to as media richness (Daft and Lengel 1986; Daft and Trevino 1987; Lengel and Daft 1988; Mohr and Nevin 1990). Lastly, content refers to the nature of the influence strategy employed within the communication (Mohr and Nevin 1990).

For effective intercultural communication across the domain of an organization's partners, the communication strategy (i.e., employment of direction, modality, frequency, and content) must take into consideration not only the macrocultural and organizational cultural influences on both the encoder and the decoder of the message but also the relationship linkage and specific communication goal. The more complex the communication environment, resulting from the levels of similarities and differences between macrocultures and organizational cultures, the more attention to ensuring effective communications strategies must be used by the originator of the message. Therefore, it is essential that those communicating across cultures and among relationships have a well-articulated method for developing communication strategies. To illustrate the type of process needed to employ an appropriate intercultural communication strategy, the following decision-making process is presented in Figure 3.

Figure 3. Developing an Intercultural Communication Strategy

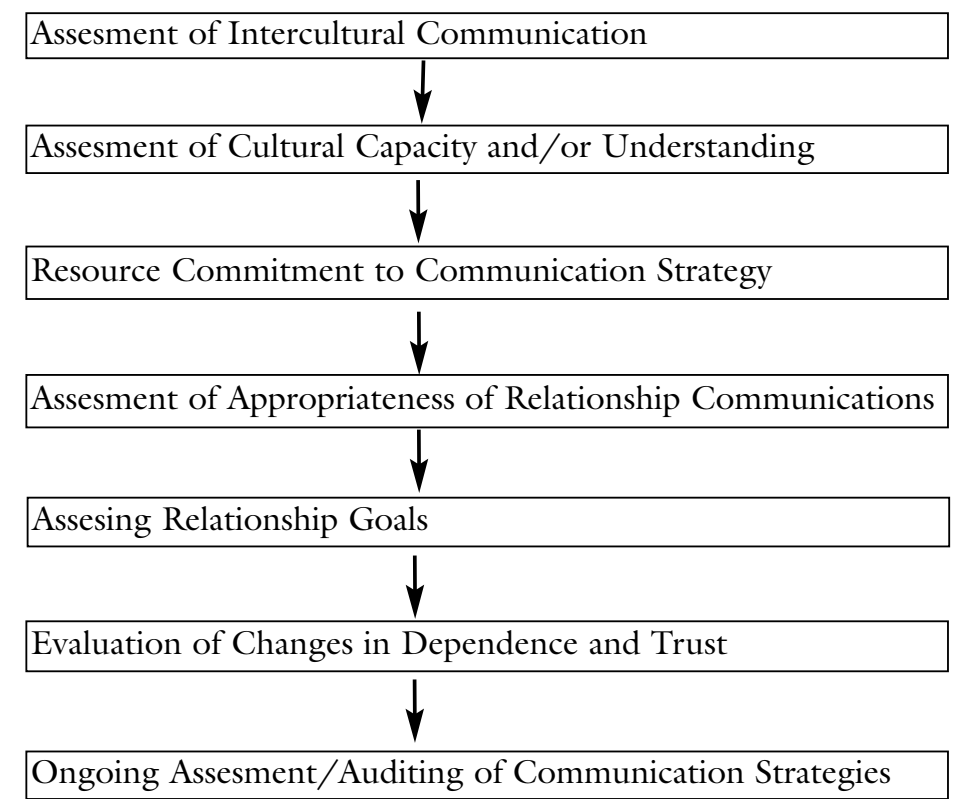




\section{ASSESSMENT OF INTERCULTURAL COMMUNICATION}

The past experience in intercultural communication of the communication strategy's initiator must be objectively assessed. This appraisal of intercultural communication must examine both the experience level, as well as the success of the organization's past communications with various partners across countries and cultures. In essence, one's competence in intercultural communication is based

Objective analysis of the communication problems indicated a low level of intercultural communication competence... . upon a set of abilities and accumulated knowledge primarily based upon developing meaningful and effective intercultural messages (Chen \& Starosta, 1995; Ceri, Van den Berg, \& Jiang, 1998).

Given the nature of the complexity of the communication environment, the developed skill set for adjusting each element of the communication strategy (i.e., issues of directionality, frequency, modality, and content) becomes critical. Those with little prior experience in highly complex communication environments must rely more heavily on bidirectional, frequent, personalized, low-content communications in order to minimize intercultural communication misunderstandings and maximize communication effectiveness. With extended intercultural exchanges, an initiator's abilities to adjust the four elements of communication are developed, resulting in more efficient and effective communications with relationship linkages. For example, when OSARM, the German lighting giant, bought the U.S. firm Sylvania, the German and U.S. engineers had trouble communicating intraorganizationally. Objective analysis of the communication problems indicated a low level of intercultural communication competence thus stimulating the development of an e-mail language translation system to facilitate understanding in the highly complex environment.

\section{ASSESSMENT OF CULTURAL CAPACITY AND/OR UNDERSTANDING}

The cultural capacity of intercultural communication is the ability of the organization to classify past intercultural experiences into meaningful categories. By doing so, the initiator's strategy can be utilized in like situations, providing some degree of economies of scale (Kim, 1988). The means for classification can be based upon different macroculture and organizational cultures, sub-divisions in both, as well as on the domain (type) of relationship. Not only is there an economy of scale established by employing similar communication strategies across domain partners, but an additional cultural empathy of the initiator is developed-reducing the level of trial and error in establishing the foundation for communication with the global partner. 
The frequency of communication between intercultural partners can accelerate the rate of adaptation of communication strategies, thereby increasing the strategies' efficiency and effectiveness (Church, 1982). For instance, compare the development of cultural understanding in two communications initiators who have differing environmental complexity. The initiator in the low-complexity environment is an efficient communicator as a result of scant adjustment in established communication strategy. Low-complexity communication environments are characterized by similarity in both macroculture and organizational culture. Because of this, the initiator can rely on relatively infrequent, high-content communication messages. However, one result of the lack of environmental complexity is a diminished rate of developing intercultural understanding. Alternatively, an initiator in a highly complex communication environment must rely more heavily on communication strategies, employing frequent, low-content, highly personalized communications to minimize communication problems. As a result, those operating in highly complex communication environments develop cultural understanding and thus are better able to adjust communication strategies across intercultural communication relationships more efficiently as a result of economies of scale.

Low-complexity communication environments are characterized by similarity in both macroculture and organizational culture.

\section{RESOURCE COMMITMENT TO COMMUNICATION STRATEGY}

Given past experiences, and some gauge of successful intercultural communications with a variety of types of partners, additional commitment of resources (i.e., time, expertise, adaptation, communications, etc.) will, frequently, escalate over time. To improve communication linkages and to help ensure ongoing relationships, additional resources will be needed to improve communication capabilities. Where to invest the capital in the communication process is the most difficult reverse allocation decision.

The commitment of resources to specific functional areas of intercultural communication should not only be considered relating to one specific relationship, but relating to the effective impact on the organization's communication linkages. The decision to commit resources to an interorganizational relationship, by definition, limits the organization's ability to commit resources to other relationships, such as its intra-organizational as well as organizational-to-customer. Thus, in order to effectively allocate communication resources, an organization's overall intercultural communication relationships 
should be examined. In doing so, an organization may wish to prioritize their intercultural linkages by: (1) level of environmental communication complexity, and (2) importance to the organization's ability to provide a continuing stream of value in the marketplace.

\section{ASSESSMENT OF APPROPRIATENESS OF RELATIONSHIP COMMUNICATIONS}

The basic posture on the communication strategy position may need to be altered relative to the goal of the intercultural relationship.
Relationship communications need to be monitored on an ongoing basis to determine their appropriateness for their intended target. For example, does the communication strategy being employed operate most effectively internally or externally? Between various domains of partners? In certain macrocultural environments? It is imperative that the communication strategy be assessed for each domain, for internal as well as with external partners, and in different cultural settings. In doing so, the areas of the communication strategy that need to be improved or modified can be identified. If the communication strategy is not disaggregated, it is very difficult to measure communication effectiveness.

\section{ASSESSING RELATIONSHIP GOALS}

The communication strategy not only has to be evaluated relative to the various types of relationship partners and macrocultural differences but also the relationship goals. The basic posture on the communication strategy position may need to be altered relative to the goal of the intercultural relationship. Therefore, managing the communication strategy should include a means to modify communication efforts that are dependent upon differences in communication targets.

Not all relationships are similar in terms of their intended goal. The type of relationship goal will vary by factors such as domain, cultural setting, or competitive environment. For example, Ford Motor Co.'s acquisition of Volvo's passenger car division required communicating to the Swedish public that Ford's intended to retain the values of the Swedish car maker in order to maintain a meaningful relationship with its customers. Alternatively, Volvo suppliers were faced with a different communication strategy, as Ford attempted to consolidate global supply for its passenger cars. Each of these situations required Ford to employ a significantly different communication strategy (i.e., direction, frequency, modality, and content) in order to achieve its desired goal. Without assessing the relative goal of each relationship 
communication linkage, it could be concluded that once a strategy has been successful in a specific intercultural relationship, it can be effectively transferred to other linkages within that culture. The communication strategy needs to tie directly to operational goals of the relationship in the context of the relationship linkage.

\section{EVALUATION OF CHANGES IN DEPENDENCE AND TRUST}

Communication strategies can be, and frequently are, influenced by the level of interaction and the resulting level of trust between partners that is developed over time. The communication strategy should be aligned with the existing trust and modified to changes in the trust level. In new intercultural relationships, increasing the trusting qualities between interacting parts can be stimulated through cross-functional teams and building an embedded social level of partnership via a well-articulated communication strategy (Sheppard, 1995; Lewicki, McAllister, \& Bies, 1998). One such example is British Petroleum. The recent merger of British Petroleum and Atlantic Richfield has been helped by an underlying global information technology infrastructure that enhances the development of relationships through communication and information sharing. Therefore, one of the primary goals of communication strategies should be directed at building trust and to overcome the inherent motives to distrust due to the intercultural nature of the relationship (Brandenburger \& Nalebuff, 1996).

\section{ONGOING ASSESSMENT/AUDITING OF COMMUNICATION STRATEGIES}

Given the complexity of establishing effective intercultural communication strategies in host countries, it becomes imperative to monitor and audit the communication strategy on a continuing basis. For example, in the recent merger creating Daimler Benz-Chrysler, at least three multicompany committees were formed to monitor communication-related issues on an ongoing basis. A communication strategy auditing process should include: (1) a service-level, crossfunctional management team responsible for the monitoring, such as that initiated by Daimler Benz-Chrysler; (2) assessment of the linkage between communication strategy and overall corporate strategy for each relationship; (3) assessment of the overall architecture of the corporate intercultural communication strategy within various dimensions of relationships; (4) evaluation of the strategy's modification over time with partners, thus necessitating the creation of a

Thunderbird International Business Review • July-August 2002

The communi-

cation strategy

should be

aligned with the

existing trust

and modified to

changes in the

trust level. 
The issue

becomes how to develop, maintain, and modify intercultural communication strategies across a wide variety of relationship domains. strategic communication plan for each partner; (5) assessment of the incorporation of new knowledge and intercultural communication experience into the competency base of the organization, possibly through the integration of information technology, such as with British Petroleum or the use of database sharing; (6) adaptation of individual communication strategies to change in the host country, host organization, and to the relationship linkage. Without monitoring the intercultural relationship communication, the likelihood of maintaining effective communications is minimal and value in the relationships cannot be maximized (Jüttner \& Werhli, 1994).

Communication strategies that are intercultural in nature are extremely complex strategies and need to be developed for individual relationships yet should maintain a consistency and coherence across relationships. This locally specific yet network-consistent attribute of communication strategy requires a high level of intercultural competency when being employed in a global network of relationships.

\section{SUMMARY/CONCLUSION}

The current process of globalization of organizations will have a profound effect on the organizations themselves as well as the individuals responsible for managing them over time. The greater the degree of globalization, the more likely the need for intercultural relationships to be formed. Due to the expansiveness of the global context of business, most organizations will not have the necessary resources or managerial skills to effectively operate in over 190 different countries. If relationships are used to bridge the gap between resources/skills and the number of countries an organization enters, then the communications that are used to tie organizations together becomes central in the general global business strategy (Duncan \& Moriarty, 1998). The issue becomes how to develop, maintain, and modify intercultural communication strategies across a wide variety of relationship domains.

Intercultural communication strategies must be developed on the basic premise that there is a domain of relationships that can be used to categorize the various types of relationships that can be entered into by an organization. Each of the various types of relationships necessitates a variance in communication strategies due to the differences in potential partner categories. For example, communications between channel-of-distribution partners differ from those with strategic partners. Recognizing these differences and effectively man- 
aging global communication strategy requires in-depth knowledge of global motivations, differences in domain characteristics and the communication differences due to the intercultural nature of the communication program. These intercultural communication tasks are difficult to devise and to modify over time.

If global relationships are to succeed and provide a competitive advantage, communications among partners need to be effective and adaptable to specific environmental conditions. Therefore, a great deal of planning, expertise, and assessment of intercultural communications must be undertaken. In many cases, managers are recognizing that traditional market mix elements used to differentiate their competitive offerings have become commodities, making their most valuable assets relationships with key global stakeholders. The importance of relationships as market-based assets in global business has become the competitive means to differentiate the global corporate strategy (Srivastava, Shervani, \& Fahey, 1998). Without effective intercultural communication capabilities, these relationships cannot be maintained or effective over time.

\section{REFERENCES}

Araujo, L., \& Mouzas, S. (1998). Manufacturer-retailer relationships in Germany: The institutionalization of category management. In P. Naude \& P. Turnbull (Eds.), Network dynamics in international marketing. Oxford, England: Pergamon Press.

Arnold, D., \& Quelch, J. (1998, Fall). New strategies in emerging markets. Sloan Management Review, 7-20.

Barney, J. (1991). Firms resources and sustained competitive advantage: A comment. Management Science, 32, 1512-1514.

Bendapudi, N., \& Berry, L. (1997). Customers' motivation for maintaining relationships with service providers. Journal of Retailing, 73(1), 15-38.

Berry, L. (1995, Fall). Relationship marketing of services: Growing interest emerging perspectives. Journal of the Academy of Marketing Science, 23, 236-245.

Berry, L. (1997). Listening to consumers: The concept of a service-quality information system. Sloan Management Review, 38(3), 65-77.

Berry, L., \& Parasuraman, A. (1991). Marketing services: Competing through quality. New York: The Free Press.

Boyle, B., Dwyer, R., Robicheaux, R., \& Simpson, J. (1992, February). Influence strategies in marketing channels: Measures and use in different relationship structures. Journal of Marketing Research, 29, 18-34.

Brandenburger, A., \& Nalebuff, B. (1996). Co-opetition. New York: Doubleday.

Brown, S., \& Bond, E. (1995). The internal market/external market framework and service quality: Toward theory in service marketing. Journal of Marketing Management, 11, 29-39.

Buckley, P., \& Casson, M. (1997). An economic model of international joint venture strategy. In P. Beamish \& J.P. Killing (Eds.), Corporate Strategies: European perspectives (pp. 267-299). San Francisco: The New Lexington Press.

Castles, S. (1997). Multicultural citizenship: A response to the dilemma of globalization and national identity. Journal of Intercultural Studies, 18(1), 5-22.

Ceri, G., Van den Berg, S., \& Jiang, Y. (1998). Cross-cultural adaptation and ethnic communication: Two structural equation models. The Howard Journal of Communications, 9, 69-85. 
Chatman, J., \& John, K. (1994, June). Assessing the relationship between industry characteristics and organizational culture: How different can you be? Academy of Management Journal, $37,522-553$.

Chen, G., \& Starosta, G. (1995). Intercultural communication competence. In B.R. Burleson (Ed.), Communication Yearbook (vol. 19, pp. 353-383). Beverly Hills, CA: Sage Publications. Church, A. (1982). Sojourner adjustment. Psychological Bulletin, 91, 540-572.

Collins, D. (1994). Research note: How valuable are organizational capabilities. Strategic Management Journal, 15(2), 143-152.

Craig, S., \& Douglas, S. (1996). Developing strategy for global markets: An evolutionary perspective. Columbia Journal of World Business, 31(2), 70-81.

Czepiel, J. (1990). Service encounters and service relationships: Implications for research. Journal of Business Research, 20, 13-21.

Daft, R., \& Lengel, R. (1986). Organizational information requirements, media richness and structural design. Management Science, 32(9), 554-571.

Daft, R., \& Trevino, L. (1987). Manager equivocality, media selection and manager per-formance: implications for information systems. MIS Quarterly, 11, 355-366.

Deshpendi, R., \& Webster, F. (1989, January). Organizational culture and marketing: Defining the research agenda. Journal of Marketing, 53, 3-15.

Doz, Y., \& Hamel, G. Alliance advantage: The art of creating value through partnering. Boston: Harvard Business School Press.

Duncan, T., \& Moriarty, S. (1998). A communication-based marketing model for managing relationships. Journal of Marketing, 62(2), 1-13.

Dwyer, R., Schurr, P., \& Oh, S. (1987, April). Developing buyer-seller relationships. Journal of Marketing, 51, 11-27.

Dyer, J., \& Singh, H. (1998). The relational view: Cooperative strategy and sources of interorganizational competitive advantage. Academy of Management Journal, 23(4), 660-679.

Fey, C., \& Beamish, P. (2000). Joint venture conflict: The case of Russian international joint ventures. International Business Review, 9, 139-162.

Florin, J. (1997). Organizing for efficiency and innovation: the case for nonequity interfirm cooperative arrangements. In P. Beamish \& J.P. Killing (Eds.), Cooperative strategies: North American perspectives (pp. 3-25). San Francisco: The New Lexington Press.

Fournier, S., Dobscha, S., \& Mick, D. (1998, January-February). Preventing the premature death of relationship marketing. Harvard Business Review, 42-51.

Garsten, C. (1993). Apple world: Core and periphery in a transnational organizational culture. Stockham: Stockham Studies in Social Anthropology.

Garten, J. (1996, Summer). The big emerging markets. The Columbia Journal of World Business, 31, 6-31.

Garten, J. (1997, May-June). Troubles ahead in emerging markets. Harvard Business Review, $38-49$.

Geringer, J. (1991). Strategic determinants of partner selection criteria in international joint ventures. Journal of International Business Studies, 22, 41-62.

Geringer, M., \& Herbert, L. (1990). Measuring performance of international joint ventures. Journal of International Business Studies, 22, 249-263.

Gilly, M., \& Wolfinbarger, M. (1998, January). Advertising's internal audience. Journal of Marketing, 62, 69-88.

Gomes-Casseres, B. (1996). The alliances revolution: The new shape of business rivalry. Cambridge, MA: Harvard University Press.

Grandori, A., \& Soda, G. (1995). Inter-firm networks: Antecedents, mechanisms and forms. Organization Studies, 16(2), 183-214.

Grönroos, C. (1994). From marketing mix to relationship marketing: Towards a paradigm shift in marketing. Management Decision, 32(2), 4-20.

Gummesson, J. (1996). Relationship marketing and imaginary organizations: A synthesis. European Journal of Marketing, 30(2), 31-44.

Gundlach, G., Achrol, R., \& Mentzer, J. (1995, January). The structural commitment in exchange. Journal of Marketing, 59, 78-92.

Gundykunst, W. (1995). Anxiety/uncertainty management AUM theory. In R. Wiseman 
(Ed.), Intercultural Communications Theory (pp. 123-156). Thousand Oaks, CA: Sage Publications.

Gundykunst, W. (1998). Individualistic and collectivistic perspectives on communication: An introduction. International Journal of Intercultural Relations, 22(2), 107-134.

Hamada, T. (1989). American enterprise in Japan. Albany, NY: State University of New York Press.

Harrigan, K. (1985). Strategies for joint venture success. Lexington, MA: Lexington Books.

Heide, H., \& John, G. (1990, February). Alliances in industrial purchasing: The determinants of joint action in buyer-seller relationships. Journal of Marketing Research, 27, 24-26.

Heide, H., \& John, G. (1992, April). Do norms matter in marketing relationships? Journal of Marketing, 56, 32-44.

Henderson, R., \& Cockburn, I. (1994, winter special issue). Measuring competence: Exploring firm effects in pharmaceutical research. Strategic Management Journal, 15.

Hofstede, G. (1980). Culture's consequences: International differences in work-related values. Beverly Hills, CA: Sage Publications.

Hofstede, G., \& Bond, H. (1998). Attitudes, values and organizational culture: Disentangling the concepts. Organization Studies, 19(3), 477-492.

Inkpen, A. (1997). An examination of knowledge management in international joint ventures. In P. Bemish \& J. P. Killing (Eds.), Cooperative strategies: North American prospectives (pp. 337-369). San Francisco: The New Lexington Press.

Jeannet, J-P. (2000). Managing with a global mindset. New York: Financial Times, Prentice Hall.

Johanson, J. (1994). Internationalization, relationships and networks. Stockholm: Uppsala University Press.

Jüttner, V., \& Wehrli, H.P. (1994). Relationship marketing from a value system perspective. International Journal of Service Industry Management, 5(5), 54-73.

Kasulis, H., \& Balazs, A. (1998). Relationship marketing: A synthesis of three research arenas. Working paper series, University of Oklahoma, Michael F. Price School of Business.

Killing, J.P. (1983). Strategies for joint venture success. New York: Praeger.

Kim, Y.Y. (1988). Communication and cross-cultural adaptation: An integrative theory. Clevedon, England: Multilingual Matters.

Lengel, R., \& Daft, R. (1988). The selection of communication media as an executive skill. Academy of Management Executives, 2, 225-232.

Lewicki, R., McAllister, D., \& Bies, R. (1998). Trust and distrust: New relationships and realities. Academy of Management Review, 23(3), 438-458.

Lewis, J. (1990). Partnership for profit: Structuring and managing strategic alliances. New York: The Free Press.

Lorange, P., \& Roos, J. (1992). Strategic alliances: Formation, implementation and evaluation. Cambridge, MA: Blackwell.

Lusch, R., Brown, J., \& Brunswick, G. (1992). A general framework for explaining internal vs. external exchange. Journal of the Academy of Marketing Science, 20(2), 119-134.

Mennell, S. (1990). The globalization of human society as a very long term social process: Elija's theory. In M. Featherstone (Ed.), Global Culture. London: Sage Publications.

Miller, K. (1999). Organizational communication: Approaches and processes. Belmont, CA: Wadsworth.

Mohr, J., and Nevin, J.R. (1990). Communication strategies in marketing channels: A theoretical perspective. Journal of Marketing, 54(4), 36-51.

Morgan, R., \& Hunt, S. (1994, July). The commitment-trust theory of relationship marketing. Journal of Marketing, 58, 36-51.

MOW. (1987). The meaning of work. [MOW Work Research Team]. London: Academic Press. Neuliep, J., \& McCroskey, J. (1997). The development of intercultural and interethnic communication apprehension scales. Communication Research Reports, 14, 145-156.

Papanastassion, M., \& Pearce, R. (1997). Cooperative approaches to strategic competitiveness through MME subsidiaries: Insiders and outsiders in the European market. In P. Beamish \& J. P. Killing (Eds.), Cooperative strategies: European perspectives (pp. 267-299). San Francisco: The New Lexington Press. 
Park, H. (1991). Analysis of joint ventures, local managers' behavior and its impact on joint venture cohesiveness: Korea case. Journal of Global Marketing, 5, 201-221.

Parkhe, A. (1998). Understanding trust in interrelational alliances. Journal of World Business, 33(3), 219-240.

Pruden, D. (1995). There's a difference between frequency marketing and relationship marketing. Direct Marketing, June, 30-31.

Reeves-Ellington, R., \& Anderson, A. (1997). The entnology of information: Cultural learning through cooperatives action research in a multinational firm. Accounting, Management \& Information Technology, 7(3), 139-168.

Rousseau, D. (1990). Quantitative assessment of organizational culture: The case for multiple measures. In B. Schneider (Ed.), Frontiers in industrial and organizational psychology. San Francisco: Jossey Bass, 153-192.

Sagrero, M., \& Schrader, S. (1998). Structuring interfirm relationships: A meta-analytic approach. Organization Studies, 19(4), 585-615.

Schein, E. (1985). Organizational culture and leadership. San Francisco: Jossey-Bass.

Schein, E. (1996). Culture: The missing concept in organizational studies. Administrative Science Quarterly, 41, 229-240.

Schwartz, S. (1994). Cultural dimensions of values: Towards an understanding of national differences. In U. Kim, H. Trandis, \& G. Yoon (Eds.), Individualism and collectivism: Theoretical and methodological issues. Newbury Park, CA: Sage Publications.

Shani, D., \& Chalasani, S. (1992, Fall). Exploiting niches using relationship marketing. Journal of Service Marketing, 6, 43-52.

Sheppard, B. (1995). Negotiating in long-term mutually inter-dependent relationships among relative equals. In R. Bies \& R. Lewicki (Eds.), Research on negotiation in organizations (vol. 5, pp. 3-44). Greenwich, CT: JAI Press.

Sheth, J., \& Parvatiyar, A. (1995, Fall). Relationship marketing in consumer markets: Antecedents and consequences. Journal of the Academy of Marketing Science, 23, 255-271.

Smith, P., Peterson, M., Lerenz, M., \& Dugen, S. (August 1996). Individualism-collectivism and the handling of disagreement: A 23 country study. Paper presented at annual meeting of the American Psychological Association, Toronto, Canada.

Spitzberg, B., \& Lane, S. (1983). Interpersonal orientations: A review, synthesis and critique. Paper presented at the Western Speech Communication Association Convention, Albuquerque, NM.

Srivastava, R., Shervani, T., \& Fahey, L. (1998, January). Market-based assets and shareholder value: A framework for analysis. Journal of Marketing, 62, 2-18.

Stalk, G., Evans, P., \& Shulman, L. (1992). Competing on capabilities: The new rules of corporate strategy. Harvard Business Review, 70, 57-69.

Teece, D., Pisano, G., \& Shuen, A. (1994). Dynamic capabilities and strategic management. Working paper, Harvard Business School.

Teece, D., Rumelt, R., Dosi, G., \& Winter, S. (1994). Understanding corporate coherence: Theory and evidence. Journal of Economic Behavior and Organization, 23, 1-30.

Tjosvold, D. (1991). Term organization: An enduring competitive advantage. New York: Wiley.

Tjosvold, D. (1993). Teamwork for customers: Building organizations that take pride in serving. San Francisco: Jossey-Bass.

Tjosvold, D., \& Wong, C. (1994). Working with customers: Cooperation and competition in relational marketing, Journal of Marketing Management, 10, 297-310.

Treacy, M., \& Wiersema, F. (1994, January-February). Customer intimacy and other value disciplines. Harvard Business Review, 84-93.

Trompenaars, F. (1993). Riding the waves of culture. London: Brealey.

Voss, G., \& Voss, Z. (1997). Implementing a relationship marketing program: A case study and managerial implications. Journal of Service Marketing, 11(4), 278-298.

Webster, F. (1992, October). The changing role of marketing in the corporation. Journal of Marketing, 56, 1-17.

Williams, J., Han, S., \& Qualls, W. (1998). A conceptual model and study of cross-cultural business relationships. Journal of Business Research, 42, 135-143.

Williamson, O. (1991). Comparative economic organizations: The analysis of discrete structural alternatives. Administrative Science Quarterly, 36, 269-296. 